\title{
ANTI-HIPERTENSORES EM ENFERMAGEM GERAL
}

\section{Djair Daniel Nakamae*}

NAKAMAE, D. D. - Anti-hipertensores em enfermagem geral. Rev. Esc. Enf. USP, 11(1):20-27, 1977.

A autora faz comentários sobre os agentes anti-hipertensivos mais usuais na enfermarià, dando especial enfoque à participação da enfermeira, que desempenha papel cada vez mais relevante para o pleno sucesso da prescrição médica.

A participação da enfermeira na terapêutica medicamentosa se vem tornando cada vez mais efetiva para o pleno êxito da prescrição médica. Muitas vezes uma só informação daquela é suficiente para o médico alterar a conduta até então seguida. Isso parece ser particularmente verdadeiro no caso dos anti-hipertensores, em que a enfermeira ajuda na seleção de agentes, pela rigorosa atenção à dose na fase de ajustamento, controle dos efeitos benéficos e dos secundários indesejáveis, bem como da motivação do paciente para uma participação adequada.

O tratamento medicamentoso anti-hipertensivo tem sido dirigido a todos os pacientes portadores de hipertensão arterial de causa reconhecida ou de causa irreconhecível. $O$ último caso engloba aproximadamente 85 a $90 \%$ da população de hipertensos, segundo estatísticas recentes. Assim, vê-se que se trata de uma terapêutica sintomática, cuja causa é, na maior parte das vezes, desconhecida tanto para o médico, que decide e prescreve o tratamento, quanto pela enfermeira, que administra e controla seus efeitos.

Os anti-hipertensores englobam um grupo bem amplo. $\mathrm{Na}$ enfermaria, geralmente, trabalha-se com um número bem restrito, pois

\footnotetext{
* Professor Assistente da Disciplina Enfermagem Médica da EEUSP.
} 
sua eficiência ainda está limitada, em grande parte, pelos efeitos colaterais ou secundários que tais drogas costumam apresentar. Entre os mais usados na clínica contam-se a reserpina, derivados tiazídicos, alfametildopa e alguns anti-adrenérgicos. Mais recentemente muitas drogas vêm sendo lançadas no mercado, mas na prescrição médica pouco aparecem. Justificam alguns médicos, que elas ainda não oferecem segurança suficiente, porque a eficiência terapêutica está pouco comprovada pelo uso e o mecanismo de ação, às vezes, pouco esclarecido. Além disso, os preços elevados afastam o paciente do uso. Neste trabalho consideram-se as drogas de uso rotineiro nas enfermarias de qualquer hospital, ficando as outras para artigo subseqüente.

A maioria dos autores define hipertensão arterial como sendo "a elevação persistente da pressão diastólica (mínima) acima de $100 \mathrm{mmHg}$ em pessoas com mais de 60 anos e acima de $90 \mathrm{mmHg}$ em pacientes com menos de 50 anos" KRUPP \& CHATTON (3). Hemodinamicamente caracteriza-se a hipertensão pela redução de calibre arteriolar, levando em consequiência a um aumento da resistência periférica. Portanto, o fenômeno hipertensivo é anatômico. Sabe-se que em cerca de $90 \%$ dos casos a causa não é detectável, ou quando detectável não é removível. Assim sendo, a medicação anti-hipertensiva, quando corretamente prescrita e administrada, eleva os anos de vida, limitando os riscos inerentes à pressão alta.

Estudos têm mostrado que a hipertensão se mantém assintomática durante muitos anos (de dez a vinte) evoluindo sem tratamento ou com tratamento inadequado para complicaçōes cardíacas, acidente cérebro-vascular trombótico ou hemorrágico e insuficiência renal.

A seleção do agente anti-hipertensivo é individual para cada paciente, pois está na dependência da resposta ao tratamento, tolerância ao medicamento e na capacidade do paciente para cooperar. Nesses três aspectos tem a enfermeira participação efetiva. E será tanto mais eficiente quanto melhor conhecer o mecanismo de ação da droga no organismo do paciente, pois desse conhecimento podem-se deduzir os efeitos clínicos benéficos esperados e que devem ser devidamente controlados para que atinjam o grau ótimo e aí se mantenham. Da mesma forma, o conhecimento do mecanismo de ação das drogas permite avaliar os efeitos secundários indesejáveis, muitas vezes temíveis. $\mathrm{O}$ controle de seu surgi- 
mento e evolução, encaminhamento precoce ao médico e orientação adequada ao paciente de como deve se cuidar e quando comunicar alterações colocam a assistência de enfermagem num ponto estratégico, facilitando o encaminhamento e o êxito terapêutico do médico clínico.

Na hipertensão primária a terapêutica é dirigida predominantemente à inibição do tono vasomotor adrenérgico e por este mecanismo reduzir a pressão arterial.

A ação dos tiazídicos

O efeito diurético dessas drogas se faz sentir na diminuição do volume extracelular e plasmático reduzindo assim o débito cardíaco, que conseqüentemente interfere na diminuição da pressão arterial. Tais drogas potencializam ainda a ação de outros anti-hipertensores. Estudos mostram que têm ação direta sobre a musculatura lisa das arteríolas (vasos de resistência), diminuindo o tono vasoconstritor simpático. Pensa-se que essa ação seja devida à diminuição de água, sódio e potássio da parede arteriolar com o que promove redução da utilização da catecolamina arteriolar. Os autores afirmam que não atuam sobre os vasos de capacitância, portanto permitem adequado retorno venoso, sem acumulação venosa e hipotensão postural na posição ereta. Contudo, seu efeito hipotensor é fraco. Precisam ser combinados com agentes mais poderosos na hipertensão moderada ou grave.

A seguir, mencionam-se seus efeitos colaterais mais comuns: a hiperurecemia, por inibir parcialmente a eliminação do ácido úrico pelas células do túbulo distal no rim, o que leva a contraindicar esse medicamento na gota; a hipopotassemia, decorrente de sua ação bloqueadora da reabsorção de sódio na alça de Henle, promovendo um aporte maior deste eletrólito na luz tubular distal, do que resulta maior permuta entre sódio e potássio, retendo o primeiro e excretando o segundo na urina.

Dentre os tiazídicos mais usuais estão a Dehidroclorotiazida (Clorana), Clorotiazida (Clotride) e Hidroclortiazida (Esidrex) e outros mais. 
Reserpina com restrições

E uma preparação de rauwolfia que, segundo KRUPP \& CHATTON (3) é em geral menos eficaz que os diuréticos tiazídicos e cujos efeitos colaterais causam maiores transtornos. A redução dos níveis pressóricos, tanto pela reserpina como pelo diurético, é lenta, levando semanas para manifestar todo o seu efeito.

Promove depressão das catecolaminas reduzindo assim as reservas periféricas e centrais. Inibe na periferia o tono simpático aí predominante, fazendo cair a resistência arteriolar. Reduz também o débito cardíaco e renal. Com isso esperam-se os efeitos clínicos benéficos na redução da pressão arterial. A bradicardia que ocorre por diminuição da atividade dos nervos cardioaceleradores é útil na taquicardia sinusal e nas palpitações dos hipertensos.

Há inibição específica dos centros vasomotores diencefálicos, o que faz diminuir o teor de serotonina, responsável pelo estado de depressão, sonolência e apatia a que são levados alguns pacientes. Esse efeito sedativo é especialmente desejável nos pacientes com forte componente neurotônico e ansioso, portadores de insônia e irritabilidade.

Os efeitos secundários desagradáveis são verificados com doses fortes e usadas por tempo prolongado. Destes, merecem maior atenção da enfermeira a depressão que pode levar o paciente ao suicídio, como já tem sido relatado na literatura médica e de enfermagem. Úlceras gastroduodenais também podem ocorrer por estimulação da secreção gástrica provocada pela droga, com hemorragias, muitas vezes, graves.

Os efeitos colaterais menores, aos quais a enfermeira deve estar igualmente atenta são: astenia e sonolência, congestão e obstrução nasal, sudorese e diarréia provenientes da predominância do parassimpático.

O aparecimento desses efeitos, quando controlados pela enfermeira e encaminhados precocemente ao médico, resultará num maior cuidado deste com as doses. 


\section{Preferência pela alfametildopa}

Encontrada no mercado com o nome de Aldomet, a alfametildopa é o medicamento de primeira escolha para hipertensos com depressão psíquica e comprometimento renal. E indicado no tratamento de hipertensão arterial moderada e tem sua ação situada entre a reserpina e a guanetidina. Mostra-se um eficaz agente anti-hipertensivo, capaz de reduzir a pressão arterial na posição deitada e ereta.

Atua reduzindo a produção de catecolaminas, principalmente na periferia, aumentando o fluxo sanguíneo renal, protegendo, portanto, a função do rim na insuficiência renal e inibindo a produção de renina.

A metildopa é largamente excretada pelo rim. Por isso, os pacientes com insuficiência renal podem responder a doses menores do que aqueles com função renal normal.

E preciso que se esteja atenta aos efeitos colaterais, como secura na boca e diarréia devidos à predominância parassimpática. Muitos pacientes experimentam sedação por dois ou três dias quando se inicia o tratamento ou quando se aumenta a dose. Deve-se esperar que aquela desapareça após atingir a dose eficaz de manutenção. Há referência na literatura de que, embora raros, a anemia hemolítica e o Coombs positivo podem ocorrer. Esses fenômenos parecem decorrer da dose, pois registrou-se incidência mais baixa em pacientes que receberam diariamente 1 grama ou menos de metildopa. Como prevenção a enfermeira deve estar atenta aos sinais clínicos e laboratoriais, que revelam as alterações citadas.

\section{A potente guanetidina}

Lançada no Brasil com o nome de Ismelina, a guanetidina pertence ao grupo dos anti-hipertensivos mais potentes é é reservada para uso na hipertensão grave. Sua ação se dá no sistema nervoso periférico, impedindo a passagem do impulso simpático das fibras terminais ao órgão efetor. Em outras palavras, trata-se de um bloqueador seletivo simpático, que impede a ação da noradrenalina pressora. Assim, há somente diminuição do espasmo arteriolar e do tono nervoso, reduzindo 
consideravelmente 0 retorno sanguíneo ao coração, com conseqüente diminuição do débito cardíaco. Isso ocorre principalmente na mudança da posição deitada para a ereta. A diminuição do débito cardíaco leva a uma redução do fluxo sanguíneo renal e da filtração glomerular, sendo, portanto, contra-indicado o seu uso na insuficiência renal.

Constituem seus efeitos colaterais ou indesejáveis a obstrução nasal, diarréia, náuseas e vômitos, ocorrendo esses últimos pelo predomínio do sistema nervoso parassimpático na motilidade digestiva. Além da hipotensão ortostática aparece também a hipotensão após exercício (mais pela manhã), acompanhada de tontura, desânimo e turvação da vista. $O$ efeito hipotensor é acentuado pelo álcool, por ambiente quente e por outras influências vasodilatadoras. Em alguns pacientes ocorre a supressão da ejaculação, embora não modifique o orgasmo e a ereção. A retenção hidrossalina pode também ocorrer, em função da queda do fluxo glomerular.

Trata-se de droga que se armazena no corpo, com efeito cumulativo. Demora de oito a dez dias para produzir o efeito desejado, não sendo por isso utilizada em emergências hipertensivas.

A hipotensão ortostática é o efeito secundário mais evidente, razão por que se aconselham os pacientes a permanecerem certo tempo em posição sentada, antes de se levantarem do leito. Os pacientes devem dormir com a cabeceira da cama em posição elevada, a fim de evitar a hipotensão ortostática matinal e para se conseguir açã̉o máxima durante as 24 horas, na fase de ajustamento da dose.

\section{$A$ indispensável cooperação}

Caracterizada a participação da enfermeira na administração da droga prescrita e na detecção, controle, evolução dos efeitos farmacológicos, tanto benéficos como secundários, e encaminhamento precoce ao médico, resta por em relevo um aspecto da assistência, talvez o mais importante: a orientação do paciente. Visa a obter plena colaboração deste por tempo indefinido, ou melhor por toda a vida. E preciso, antes de tudo, assinalar que a interrupção do tratamento se deve em grande parte à carência de informação adequada por parte do paciente, mal-estar causado pelos efeitos colaterais da medicação, sensação de cura 
após a medicação, falta de apoio familiar, alto custo das drogas, recusa em considerar-se doente, tratamento de longo prazo, baixo nível cultural impedindo a perfeita compreensão do problema.

O tema básico para motivar o paciente consiste no esclarecimento acerca dos riscos inerentes à evolução natural da hipertensão a longo prazo e das possibilidades de prevenir tais riscos. Aqui vale muito a habilidade da enfermeira em saber situar o problema em cada caso individual, em termos de alerta e de esperança. Pickering, por exemplo, condena a atitude dos médicos que amedrontam seus pacientes, realçando a gravidade da situação e a possibilidade de súbitas complicações, caso não sigam rigorosamente $o$ tratamento. Essa atitude poderá aumentar a tensão emocional e constituir-se em fator de persistência da hipertensão.

O hipertenso, geralmente, é um indivíduo de personalidade peculiar, necessitando de amparo psicológico freqüente. Se a enfermeira está verdadeiramente convencida de que a redução dos níveis pressóricos é benéfica ao paciente, sentirá que é sua obrigação encontrar uma forma de fazer com que ele prossiga com o tratamento sem nenhuma interrupção. Deve informá-lo que a hipertensão, em geral, não representa risco iminente, mas que pode contribuir para o surgimento de complicações a longo prazo. E essencial motivar o paciente para tomar os medicamentos, com afirmativas integralmente verdadeiras: "os remédios não curam, apenas controlam a pressão arterial e prolongam a vida". Para essas informações é preciso criar um clima de confiança, conscientizá-lo, sem assustar, da absoluta necessidade de cooperar no tratamento. Há que ouvir com paciência suas queixas quanto ao efeito das drogas para instruí-lo a respeito do fato de que alguns sintomas que aparecem no início do tratamento se devem à medicação e serão aliviados à medida que as doses venham a ser ajustadas.

Conquistar a participação esclarecida do paciente talvez seja a maneira mais efetiva da enfermeira contribuir para o pleno êxito da terapêutica anti-hipertensiva. Corre-se o risco de perder, após a alta, toda a exaustiva assistência realizada na enfermaria, se o paciente é abandonado à sua própria decisão sem clara compreensão da gravidade do problema e ignorando como cuidar-se. Isso, porém, não ocorrerá, se, uma vez plenamente informado, o paciente tornar-se participante, assumindo o lugar da enfermeira no seu auto-cuidado, retornando às consul- 
tas periódicas para avaliação clínica e laboratorial, tomando regularmente a medicação prescrita e controlando os efeitos benéficos e adversos.

NAKAMAE, D. D. - Anti-hipertensive agents en general nursing. Rev. Esc. Enf. USP, 11(1):20-27, 1977.

The author comments about the more commonly used anti-hipertensive agents in the nurse-yard, emphasizing the nurse's participation which becomes gradually more important for the complete success of the medical prescription.

\section{BIBLIOGRAFIA}

1. CHIAVERINI, R. - Hipertensão arterial. Atualidades Médicas: 53-61, dez. 1975.

2. GOODMAN, L. S. \& GILMAN, S. - As bases farmacológicas da terapêutica. Rio de Janeiro, Guanabara Koogan, 1973.

3. KRUPP, M. A: \& CHATTON, M. J. - Diagnóstico clínico y tratamento clínico. México, Editorial El Manual Moderno, 1976.

4. SAAD, E. A. - Tratamento da hipertensão arterial. Revista Cardiologia Atual, Suplemento de Atualidades Médicas, maio, 1974. 